East African Medical Journal Vol. 77 No. 10 October 2000

SOCIO-DEMOGRAPHIC CORRELATES OF MENTAL AND BEHAVIOURAL DISORDERS OF CHILDREN IN SOUTHERN ETHIOPIA

Y. Ashenafi, MD, MPH, D. Kebede, MD, ScD, Department of Community Health, Addis Ababa University , M. Desta, MD and A. Alem, MD, PhD, Amanuel Psychiatric

Hospital, Addis Ababa, Ethiopia.

Request for reprints to: Professor D. Kebede, P.O. Box 31048, Addis Ababa, Ethiopia.

\title{
SOCIO-DEMOGRAPHIC CORRELATES OF MENTAL AND BEHAVIOURAL DISORDERS OF CHILDREN IN SOUTHERN ETHIOPIA
}

\author{
Y. ASHENAFI, D. KEBEDE, M. DESTA and A. ALEM
}

\begin{abstract}
Objective: To describe the magnitude and socio-demographic correlates of specific mental and behavioural disorders.

Design: A cross-sectional survey.

Setting: Butajira district, southern Ethiopia.

Participants: The Amharic version of the Diagnostic Instrument for Children and Adolescents (DICA) was used to interview parents of 1,477 children.

Main outcome measures: Attention Deficit Hyperactivity Disorder (ADHD), Disruptive behaviour disorders, mood and anxiety disorders.

Results: Using a multivariate logistic model, age was significantly associated with ADHD. Children between 10 and 14 years of age had more than three-fold increased risk of ADHD compared to younger children: adjusted odds ratio and $95 \%$ confidence interval (OR, $95 \%$ CI $=3.17(1.16,8.67), p=0.02$. Residence in urban area was also significantly associated with ADHD: adjusted OR $(95 \%$ CI $)=2.84$ (1.14-7.07), $p=0.03$. Disruptive behaviour disorders were significantly associated with increasing age: adjusted $O R(95 \% \mathrm{CI})=4.24(1.43,12.6)$. Mood and anxiety disorders were not significantly associated with any of the sociodemographic variable studied.

Conclusion: The study shows that age and residence in urban areas are significant correlates of behavioural disorders in children.
\end{abstract}

\section{INTRODUCTION}

Description of socio-demographic correlates of mental and behavioural disorders in children is important for designing a meaningful and useful policy and strategy to tackle these common health problems. The few studies on the prevalence of mental and behavioural disorders in children in Ethiopia(1-3) did not address the issue of socio-demographic correlates because of design problems.

Although Attention Deficit Hyperactivity Disorders (ADHD) is probably the best studied of the mental disorders in children(4), there is no report of studies on this disorder in Ethiopia. Similarly, disruptive behaviour disorders such as conduct disorders (CD) and oppositional defiant disorder (ODD) are among the most commonly diagnosed disorders in children in developed countries(5), but not well studied in Ethiopia. Reports of studies on mood and anxiety disorders in the country are also very few.

This is the second report of a survey conducted in Butajira, Southern Ethiopia, to describe the magnitude and socio-demographic correlates of specific mental and behavioural disorders. The objectives of the study were to describe the magnitude of specific mental and behavioural disorders in children in a rural area, and to determine their socio-demographic correlates. Diagnostic instrument for children and adolescents (DICA) has been in use in developed countries for more than two decades. It is, however, for the first time that it is applied in a communitybased survey in Ethiopia. We used Amharic translated version of DICA that has previously been evaluated for its reliability and acceptability (6).

\section{MATERIALS AND METHODS}

The study was conducted between January and December 1998 in Butajira district of Southern Ethiopia, $150 \mathrm{~km}$ south of Addis Ababa. The district has a population of 227,135. Forty five per cent of the population belong to the 15-49 year age group(7). The district is administratively divided into 87 sub-districts. Four of these are in Butajira town. The methods followed have been detailed in the first part of the report, but are stated briefly below.

A total of 120 children were screened in 60 households in each of the ten study communities by a systematic sampling procedure. Interviewers were recruited from among residents of the communities. All had completed high school, and had fieldwork experience. There were two supervisors and eight interviewers. Five of the interviewers were females. All were native speakers of the local languages, and were also fluent in Amharic, which was the medium of interview. Intensive training was conducted for one month. The training process was supervised and complemented by a psychiatrist, who had participated in the translation of DICA into Amharic. 
The translated Amharic version of DICA parent version was used. Parents or caretakers of the study children were interviewed. Data were collected for three months by eight interviewers going from house to house. Either of the parents (father or mother), or any other caretakers available, were interviewed. In situations when both father and mother were available, they were asked to choose one of them for the interview.

Data were entered using a software programme of DICA$\mathrm{R}$, which had a capacity of scoring and exporting diagnosis. Statistical analysis was then performed with Statistical Analysis System (SAS). For purposes of analysis CD and ODD were put together as disruptive behaviour disorders; phobia, general anxiety and post-traumatic stress disorders as anxiety disorders; and major depression, mania and dysthymia as mood disorders.

The logistic regression method was employed to adjust relative risks for potential confounding variables. Thus specific mental disorders were included in the logistic model as dependent variables. As independent variables the following were included in the model: sex, age (5-9/10-14), residence (urban/rural) in addition to other socio-demographic variables being assessed.

\section{RESULTS}

A total of 718 care takers/parents of 1,477 children between 5 and 15 years of age were interviewed. The response rate was $99.8 \%$. Of the total 1,477 children, $49.4 \%$ were females and $51.0 \%$ were in the age group 10 to 15 years. Most of the study subjects (98\%) were from the "Guragie" ethnic group and came from rural areas (86.3\%). Households with large family size (six and above) represented $86.4 \%$ of households. Most of the study subjects were Muslims by religion (74.3\%). Also, most of the parents were married couples (89\%) and lived in huts with thatched roof, a single room with no windows $(81.2 \%)$.

Using a multivariate logistic model, age was significantly associated with Attention Deficit Hyperactivity Disorder (ADHD). Children between 1014 years of age had more than three-fold increased risk of ADHD compared to younger children: adjusted odds ratios and $95 \%$ confidence interval $(\mathrm{OR}, 95 \% \mathrm{CI})=3.17$ $(1.16,8.67), \mathrm{p}=0.02$. Residence in urban area was also significantly associated with ADHD: adjusted OR (95\% CI) $=2.84$ (1.14-7.07), $\mathrm{p}=0.03$ (Table 1).

Disruptive behaviour disorders were significantly associated with increasing age: adjusted OR $(95 \% \mathrm{CI})=4.24$ $(1.43,12.6)$ (Table 2).

Table 1

Socio-demographic correlates of Attention Deficit Hyperactivity Disorders (ADHD) in children

\begin{tabular}{|c|c|c|c|c|c|}
\hline \multirow[t]{2}{*}{ Characteristic } & \multicolumn{2}{|c|}{ No $(\%)$} & \multirow{2}{*}{$\begin{array}{l}\text { Crude odds ratio } \\
\text { (95\% of Confidence interval) }\end{array}$} & \multirow{2}{*}{$\begin{array}{c}\text { Adjusted odds ratio* } \\
\text { (95\% Confidence interval) }\end{array}$} & \multirow{2}{*}{ P-value } \\
\hline & With disorder & Without disorder & & & \\
\hline \multicolumn{6}{|l|}{ Age (years) } \\
\hline $5-9$ & $5(0.69)$ & 719 & $1.0^{* *}$ & 1.0 & - \\
\hline $10-14$ & $17(2.26)$ & 736 & $3.32(1.15,10.33)$ & $3.17(1.16,8.67)$ & 0.02 \\
\hline \multicolumn{6}{|l|}{ Sex } \\
\hline Male & $11(1.47)$ & 737 & 1.0 & 1.0 & \\
\hline Female & $11(1.51)$ & 718 & $1.03(0.41,2.56)$ & $1.00(0.43,2.33)$ & NS*** \\
\hline \multicolumn{6}{|l|}{ Residence: } \\
\hline Rural & $15(1.18)$ & 1,261 & 1.0 & 1.0 & \\
\hline Urban & $7(3.48)$ & 194 & $3.03(1.11,8.04)$ & $2.84(1.14,7.07)$ & 0.03 \\
\hline \multicolumn{6}{|l|}{ Religion: } \\
\hline Muslim & 15 (1.37) & 1,082 & 1.0 & 1.0 & \\
\hline Others & $7(1.84)$ & 373 & $1.35(0.50,3.56)$ & $1.28(0.51,3.17)$ & NS \\
\hline \multicolumn{6}{|l|}{ Father's education } \\
\hline Not literate & $12(1.17)$ & 1,013 & 1.0 & 1.0 & \\
\hline Literate & $10(2.21)$ & 442 & $1.91(0.82,4.44)$ & $1.87(0.63,5.59)$ & NS \\
\hline \multicolumn{6}{|l|}{ Mother's education } \\
\hline Not literate & $17(1.29)$ & 1,298 & 1.0 & 1.0 & \\
\hline Literate & $5(3.09)$ & 157 & $2.43(0.77,7.13)$ & $1.87(0.63,5.59)$ & NS \\
\hline \multicolumn{6}{|l|}{ Marital status } \\
\hline Married & $20(1.54)$ & 1,278 & 1.0 & 1.0 & \\
\hline Other & $2(1.12)$ & 177 & $1.38(0.32,5.97)$ & $1.59(0.37,6.93)$ & NS \\
\hline \multicolumn{6}{|l|}{ Family size } \\
\hline Below six & $8(1.64)$ & 481 & 1.0 & 1.0 & NS \\
\hline Six and above & $14(1.42)$ & 974 & $0.86(0.34,2.26)$ & $0.82(0.34,2.00)$ & NS \\
\hline \multicolumn{6}{|l|}{ Housing condition } \\
\hline Roof : thatched & $15(1.25)$ & 1,185 & 1.0 & 1.0 & \\
\hline Corrugated & $7(2.53)$ & 270 & $2.05(0.75,5.41)$ & $0.60(0.11,3.45)$ & NS \\
\hline Room: single & $14(1.22)$ & 1,137 & 1.0 & 1.0 & \\
\hline More & $8(2.45)$ & 318 & $2.04(0.78,5.24)$ & $1.08(0.32,3.63)$ & NS \\
\hline Window: None & $16(1.26)$ & 1,249 & 1.0 & 1.0 & \\
\hline One or more & $6(2.83)$ & 206 & $2.27(0.79,6.27)$ & $1.11(0.30,4.05)$ & NS \\
\hline
\end{tabular}

*Variables included in the logistic model: age, sex and address, in addition to the variables stated above

**Reference value

$* * * \mathrm{NS}=$ Not significant 
Table 2

Socio-demographic correlates of Disruptive Behaviour Disorders (Conduct and Oppositional Deviant Disorders) in children

\begin{tabular}{|c|c|c|c|c|c|c|}
\hline \multirow{2}{*}{ Characteristic } & & \multicolumn{2}{|c|}{ No $(\%)$} & \multirow{2}{*}{$\begin{array}{c}\text { Crude odds ratio } \\
\text { (95\% Confidence interval) }\end{array}$} & \multirow{2}{*}{$\begin{array}{c}\text { Adjusted odds ratio* } \\
\text { (95\% Confidence interval) }\end{array}$} & \multirow[t]{2}{*}{ P-value } \\
\hline & & With disorder & Without disorder & & & \\
\hline \multirow{2}{*}{ Age (years): } & $5-9$ & $4(0.55)$ & 720 & $1.0^{* * *}$ & 1.0 & \\
\hline & $10-14$ & $18(2.39)$ & 735 & $4.41(1.40,15.45)$ & $4.24(1.43,12.6)$ & 0.01 \\
\hline \multirow[t]{2}{*}{ Sex: } & Male & $10(1.34)$ & 738 & 1.0 & 1.0 & \\
\hline & Female & $12(1.65)$ & 717 & $1.24(0.50,3.10)$ & $1.20(0.51,2.80)$ & NS*** \\
\hline \multirow[t]{2}{*}{ Residence: } & Rural & $16(1.25)$ & 1,260 & 1.0 & 1.0 & \\
\hline & Urban & $6(2.99)$ & 195 & $2.42(0.84,6.68)$ & $2.23(0.86,5.81)$ & NS \\
\hline \multirow[t]{2}{*}{ Religion: } & Muslim & $17(1.55)$ & 1,080 & 1.0 & 1.0 & \\
\hline & Others & $5(1.32)$ & 375 & $0.85(0.27,2.46)$ & $0.80(0.29,2.19)$ & NS \\
\hline \multicolumn{7}{|c|}{ Father's education } \\
\hline & Not literate & $13(1.27)$ & 1,012 & 1.0 & 1.0 & \\
\hline & Literate & $9(1.99)$ & 443 & $1.58(0.62,3.98)$ & $1.39(0.57,3.38)$ & NS \\
\hline \multicolumn{7}{|c|}{ Mother's education } \\
\hline & Not literate & $18(1.37)$ & 1,297 & 1.0 & 1.0 & \\
\hline & Literate & $4(2.47)$ & 158 & $1.82(0.52,5.81)$ & $1.50(0.46,4.87)$ & NS \\
\hline \multicolumn{2}{|c|}{ Marital status: Married } & $20(1.54)$ & 1,278 & 1.0 & 1.0 & \\
\hline & Other & $2(1.12)$ & 177 & $1.39(0.32,5.98)$ & $1.55(0.36,6.73)$ & NS \\
\hline \multirow[t]{2}{*}{ Family size } & Below six & $6(1.23)$ & 483 & 1.0 & 1.0 & \\
\hline & Six and above & $16(1.42)$ & 972 & $1.33(0.48,3.81)$ & $1.30(0.50,3.38)$ & NS \\
\hline \multicolumn{7}{|c|}{ Housing condition } \\
\hline & Roof : thatched & $16(1.33)$ & 1,184 & 1.0 & 1.0 & \\
\hline & Corrugated & $6(2.17)$ & 271 & $1.64(0.57,4.50)$ & $0.52(0.09,3.17)$ & NS \\
\hline & Room: single & $15(1.30)$ & 1,136 & 1.0 & 1.0 & \\
\hline & More & $7(2.15)$ & 319 & $1.66(0.61,4.38)$ & $0.96(0.28,3.30)$ & NS \\
\hline & Window: None & $17(1.34)$ & 1,248 & 1.0 & 1.0 & \\
\hline & One or more & $5(2.36)$ & 207 & $1.77(0.57,5.18)$ & $0.94(0.24,3.64)$ & NS \\
\hline
\end{tabular}

*Variables included in the logistic model: age, sex and address, in addition to the variables stated above

**Reference value: $* * * N S=$ Not significant

Table 3

Socio-demographic correlates of Anxiety Disorders (Phobia, General anxiety and Post-traumatic Stress Disorders) in children

\begin{tabular}{|c|c|c|c|c|c|c|}
\hline \multirow[t]{2}{*}{ Characteristic } & & \multicolumn{2}{|c|}{ No $(\%)$} & \multirow{2}{*}{$\begin{array}{c}\text { Crude odds ratio } \\
\text { (95\% Confidence interval) }\end{array}$} & \multirow{2}{*}{$\begin{array}{c}\text { Adjusted odds ratio* } \\
\text { (95\% Confidence interval) }\end{array}$} & \multirow[t]{2}{*}{ P-value } \\
\hline & & With disorder & Without disorder & & & \\
\hline \multirow[t]{2}{*}{ Age (years): } & $5-9$ & $12(1.66)$ & 712 & $1.0^{* *}$ & 1.0 & \\
\hline & $10-14$ & $12(1.60)$ & 741 & $0.96(0.40,2.30)$ & $0.92(0.41,2.07)$ & NS*** \\
\hline \multirow[t]{2}{*}{ Sex: } & Male & $10(1.34)$ & 738 & 1.0 & 1.0 & \\
\hline & Female & $14(1.92)$ & 715 & $1.45(0.60,3.52)$ & $1.44(0.63,3.27)$ & NS \\
\hline \multirow[t]{2}{*}{ Residence: } & Rural & $185(1.40)$ & 1,258 & 1.0 & 1.0 & \\
\hline & Urban & $6(3.00)$ & 195 & $2.15(0.75,5.83)$ & $2.16(0.84,5.50)$ & NS \\
\hline \multirow[t]{2}{*}{ Religion: } & Muslim & $18(1.64)$ & 1,079 & 1.0 & 1.0 & \\
\hline & Others & $6(1.58)$ & 374 & $0.96(0.34,2.59)$ & $0.92(0.36,2.34)$ & NS \\
\hline \multicolumn{7}{|c|}{ Father's education } \\
\hline & Not literate & $13(1.27)$ & 1,012 & 1.0 & 1.0 & \\
\hline & Literate & $11(2.43)$ & 441 & $1.94(0.81,4.65)$ & $1.76(0.77,4.04)$ & NS \\
\hline \multicolumn{7}{|c|}{ Mother's education } \\
\hline & Not literate & $19(1.44)$ & 1,296 & 1.0 & 1.0 & \\
\hline & Literate & $5(3.09)$ & 157 & $2.17(0.70,6.27)$ & $1.76(0.77,4.05)$ & NS \\
\hline \multicolumn{2}{|c|}{ Marital status:Married } & $21(1.62)$ & 1,277 & 1.0 & 1.0 & \\
\hline & Other & $3(1.68)$ & 177 & $1.04(0.31,3.51)$ & $0.96(0.28,3.30)$ & NS \\
\hline \multirow[t]{2}{*}{ Family size } & Below six & $4(0.82)$ & 485 & 1.0 & 1.0 & \\
\hline & Six and above & $20(2.02)$ & 968 & $2.51(0.80,5.52)$ & $1.93(0.50,7.52)$ & NS \\
\hline \multicolumn{7}{|c|}{ Housing condition } \\
\hline & Roof : thatched & $4(1.22)$ & 1,137 & 1.0 & 1.0 & \\
\hline & Corrugated & $8(2.89)$ & 269 & $2.20(0.85,5.52)$ & $1.93(0.50,7.52)$ & NS \\
\hline & Room: single & $4(1.22)$ & 1,137 & 1.0 & 1.0 & \\
\hline & More & $10(3.07)$ & 316 & $2.57(1.13,5.84)$ & $2.42(0.37,6.69)$ & NS \\
\hline & Window: None & $19(1.50)$ & 1,246 & 1.0 & 1.0 & \\
\hline & One or more & $5(2.36)$ & 207 & $1.58(0.51,4.56)$ & $2.42(0.87,6.69)$ & NS \\
\hline
\end{tabular}

*Variables included in the logistic model: age, sex and address, in addition to the variables stated above

$* *$ Reference value; $* * * \mathrm{NS}=$ Not significant 
Table 4

Socio-demographic correlates of Mood Disorders (Major Depression, Mania and Dysthymia) in children

\begin{tabular}{|c|c|c|c|c|c|}
\hline \multirow[t]{2}{*}{ Characteristic } & \multicolumn{2}{|c|}{ No $(\%)$} & \multirow{2}{*}{$\begin{array}{c}\text { Crude odds ratio } \\
\text { (95\% Confidence interval) }\end{array}$} & \multirow{2}{*}{$\begin{array}{c}\text { Adjusted odds ratio* } \\
\text { (95\% Confidence interval) }\end{array}$} & \multirow[t]{2}{*}{ P-value } \\
\hline & With disorder & Without disorder & & & \\
\hline \multicolumn{6}{|l|}{ Age (years) } \\
\hline $5-9$ & $4(0.55)$ & 720 & $1.0 * *$ & 1.0 & \\
\hline $10-14$ & $11(1.46)$ & 742 & $2.67(0.78,9.97)$ & $2.64(0.84,8.36)$ & NS*** \\
\hline \multicolumn{6}{|l|}{ Sex } \\
\hline Male & $6(0.80)$ & 742 & 1.0 & 1.0 & \\
\hline Female & $9(1.23)$ & 720 & $1.55(0.50,4.90)$ & $1.50(0.53,4.26)$ & NS \\
\hline \multicolumn{6}{|l|}{ Residence: } \\
\hline Rural & $13(1.02)$ & 1,263 & 1.0 & 1.0 & \\
\hline Urban & $2(1.00)$ & 199 & $0.98(0.22,4.30)$ & $0.92(0.20,4.10)$ & NS \\
\hline \multicolumn{6}{|l|}{ Religion: } \\
\hline Muslim & $12(1.09)$ & 1,085 & 1.0 & 1.0 & \\
\hline Others & $3(0.79)$ & 377 & $0.72(0.16,2.75)$ & $0.70(0.20,2.50)$ & NS \\
\hline \multicolumn{6}{|l|}{ Father's education } \\
\hline Not literate & $10(0.98)$ & 1,015 & 1.0 & 1.0 & \\
\hline Literate & $5(1.11)$ & 447 & $1.14(0.34,3.63)$ & $1.15(0.38,3.47)$ & NS \\
\hline \multicolumn{6}{|l|}{ Mother's education } \\
\hline Not literate & $12(0.91)$ & 1,303 & 1.0 & 1.0 & \\
\hline Literate & $3(1.85)$ & 159 & $2.05(0.45,7.89)$ & $2.34(0.61,9.02)$ & NS \\
\hline \multicolumn{6}{|l|}{ Marital status } \\
\hline Married & $14(1.08)$ & 1,284 & 1.0 & 1.0 & \\
\hline Other & $1(0.56)$ & 179 & $0.51(0.07,3.94)$ & $0.50(0.06,3.86)$ & NS \\
\hline \multicolumn{6}{|l|}{ Family size } \\
\hline Below six & $4(0.82)$ & 485 & 1.0 & 1.0 & \\
\hline Six and above & $11(1.10)$ & 977 & $1.37(0.40,5.10)$ & $1.41(0.45,4.48)$ & NS \\
\hline \multicolumn{6}{|l|}{ Housing condition } \\
\hline Roof : thatched & $13(1.08)$ & 1,187 & 1.0 & 1.0 & \\
\hline Corrugated & $2(0.72)$ & 275 & $0.66(0.10,3.11)$ & $0.33(0.03,4.17)$ & NS \\
\hline Room: single & $12(1.04)$ & 1,139 & 1.0 & 1.0 & \\
\hline More & $3(0.92)$ & 323 & $0.88(0.20,3.37)$ & $0.81(0.16,3.94)$ & NS \\
\hline Window: None & $14(1.11)$ & 1,251 & 1.0 & 1.0 & \\
\hline One or more & $1(0.47)$ & 211 & $0.42(0.02,3.08)$ & $0.28(0.03,2.98)$ & NS \\
\hline
\end{tabular}

*Variables included in the logistic model: age, sex and address, in addition to the variables stated above

**Reference value

$* * * N S=$ Not significant

Mood and anxiety disorders were not significantly associated with any of the socio-demographic variable studied (Tables 3 and 4).

\section{DISCUSSION}

The study shows that age and residence in urban areas are significant correlates of behavioural disorders in children. Our results are unlikely to be due to selection or information bias, as we have used a random procedure to select study subjects and employed a highly structured instrument for interviewing their parents. We have also adjusted for potential confounding variables in a multivariate logistic model.

As ADHD is difficult to correctly diagnose in preschool children, our finding of a three-fold increase in the prevalence in older children is to be expected and agrees well with other reports(8). Socio-demographic correlates of ADHD reported in the literature include: male sex, marital status (not married) and low socio-economic class(4). Sex was not associated with ADHD in the present study. This could be due to the fact that ADHD prevalence is similar between the sexes in this population. On the other hand, we could not rule out the possibility of a reporting bias. The inattentive subtype of ADHD in boys may not be easily recognised by parents or teachers. A restrictive and punitive environment both at home and the school may also discourage expression of impulsive behaviour among ADHD children. It has also been noted that the sex difference reported in the literature could be due to an ascertainment bias. Different cultural expectation and higher rate of complicating conduct disorders among boys may preferentially bring boys to the attention of health workers and researchers.

Although we have not attempted to measure SES by inquiring into income levels of households, we have measured several variables which indicate SES levels. These include, educational level of parents, family size and characteristics of houses. The results indicate that low SES is not associated with ADHD. We have also reported an association of residence in urban areas and ADHD. This association is independent of age and indicators of SES. This could be due to the fact that urban parents may have a better opportunity of recognising ADHD than rural 
parents, as the school enrolment is higher in urban areas than rural.

In our study age was significantly associated with disruptive behavioural problems. This tallies well with what is reported in the literature. Chronic marital disturbance, low income and overcrowding have also been reported in the literature as risk factors in the literature(9). All indicators of SES, marital status and family size were not associated with the disorder in the present study. As with ADHD, this could be a result of a reporting bias, although we cannot rule out the possibility that there may actually be no association between these variables and disruptive behaviour disorders.

We have lumped together phobia, generalised anxiety disorders and post-traumatic stress disorders as anxiety disorders to measure their socio-demographic correlates. None of these variables were significantly associated with the disorders. This could be the result of the lumping together of potentially distinct and unrelated disorders. Desegregation of these disorders was not possible because of the relatively few number of cases in the study.

None of the socio-demographic factors were significantly associated with mood disorders in our study. Acute and chronic life events such as divorce and death have been reported as risk factors in other studies, although no major socio-demographic correlate has been reported(10).

In conclusion, the present study showed that age and residence in urban areas are significant correlates of behavioural disorders in children. The results of this study indicate the need for further studies, using structured interview instruments, in other population groups in the country. Such data are required if a rational mental health policy towards the needs of children and adolescents is to be worked out.

\section{ACKNOWLEDGEMENTS}

Financial assistance for the study was obtained from the Rockefeller Foundation. Material assistance was obtained from the Department of
Community Health, Addis Ababa University. We would like to acknowledge Dr. Teshome Shibre and Dr. Daniel Fekadu, for sharing with us their field research experience. We also thank Ato Yemiru Teka, in organising the fieldwork and Ato Solomon T/Mariam for his assistance in the training of field workers. Ato Million, W/o Tsigie, Ato Solomon Lemessa, Ato Mesfin Kebede, Ato Nigussu Worku, Ato Wondwosen Bekele, W/o Meliha Reshid and Ato Lemma Gonfa are also acknowledged for their assistance in data processing and preparation of the manuscript. We would also like to gratefully acknowledge the parents and care takers of study children for their time and patience in completing the interview.

\section{REFERENCES}

1. Giel R., Bishaw M. and Van Luijik J.N. Behavioral disorder in Ethiopian children.J. Child Psychiat. Neurol. 1969; 72: 395-400.

2. Mulatu M.S. Prevalence and risk factors of psycho-pathology in Ethiopian children. J. Amer. Acade. Child Adolesc. Psychiat. 1995; 34:10-109.

3. Tadesse B., Kebede D., Tegegne T. and Alem A. Childhood behavioural disorders in Ambo district, western Ethiopia. I. Prevalence estimates Acta Psychiatrica Scandinavica 1999; 100:92-97.

4. Arnold LE and Jensen PS. Attention-deficit disorders. In Kaplan HI and Sadock BJ (eds) Comprehensive Textbook of Psychiatry. Sixth Edition. Volume 2. Chapter 38. William \& Wilkins, Baltimore, 1995: 2295-2310

5. Vitiello B. and Jensen P.S. Disruptive behavior disorders. Kaplan H.I. and Sadock B.J. (eds) Comprehensive Textbook of Psychiatry. Sixth Edition. Volume 2. Chapter 39. William \& Wilkins, Baltimore, 1995:2311-2319

6. Kebede M. Evaluation of the reliability, acceptability and feasibility of the Amharic Version of the Diagnostic Interview for Children and Adolescents (DICA). M.P.H. Thesis, Addis Ababa University, 1997.

7. OPHCC, Office of the Population and Housing Census Commission. The 1994 Population and Housing Census of Ethiopia. Results for Southern Nations, Nationalities and Peoples' Region. Volume 1: Part V. Abridged Statistical Report. Addis Ababa, 1996.

8. Barkley R.A. Attention-Deficit Hyperactivity Disorder: A handbook for Diagnosis and Treatment. The Guilford Press, New York, 1990:61.

9. Earls F. Oppositional Defiant and Conduct Disorder: Modern approaches, in Rutter M., Taylor E., Hersov L., (eds). Child and Adolescent Psychiatry, third edition. 1995: 315.

10. Harrington R. Affective Disorders, in Rutter M., Taylor E., and Hersov L. (eds) Child and Adolescent Psychiatry: Modern approaches, third edition, 1995: 330-350. 